Published in final edited form as:

Soc Sci Res. 2015 July ; 52: 570-587. doi:10.1016/j.ssresearch.2015.04.006.

\title{
The Consequences of Job Displacement for Health: Moderating Influences of Economic Conditions and Educational Attainment
}

\author{
Jessica Pearlman \\ University of North Carolina, Chapel Hill, Department of Sociology 155 Hamilton Hall CB \#3210 \\ UNC-CH Chapel Hill, NC 27599-3210
}

Jessica Pearlman: pearlman@live.unc.edu

\begin{abstract}
This paper will examine the impact of worker displacement on health in the United States from 1975-2004, especially the extent to which the impact of displacement on health varies according to the economic conditions in the year of displacement and the education level of the displaced worker. Findings from ordered probit and fixed effects models suggest that the negative impact of displacement on health is exacerbated by a higher unemployment rate at the time of displacement and for displaced workers with a college degree.
\end{abstract}

\section{Keywords}

Job Displacement; Health; Education; Economic Conditions

\section{Introduction}

Over the past several decades, and especially during the past few years, the phenomena of job loss and the subsequent consequences for individuals and families have become topics of frequent debate among academics, policy makers and the media. While much of the discussion focuses on the economic and financial consequences of job loss, more recently attention has also been paid to the consequences that job loss can have for physical health. This paper furthers this discussion by exploring the manner in which the health consequences of job loss are moderated by the educational attainment of the displaced worker as well as the larger macro-economic context in which the job loss occurs. The moderating effect of macro-economic conditions is of particular relevance given the current long-term period of continual high unemployment in the United States.

(C) 2015 Published by Elsevier Inc.

Publisher's Disclaimer: This is a PDF file of an unedited manuscript that has been accepted for publication. As a service to our customers we are providing this early version of the manuscript. The manuscript will undergo copyediting, typesetting, and review of the resulting proof before it is published in its final citable form. Please note that during the production process errors may be discovered which could affect the content, and all legal disclaimers that apply to the journal pertain. 


\section{Background}

\subsection{Recessions and Job Loss}

Economic recessions typically result in large numbers of involuntary job losses among individuals who in more prosperous times experience long term stable employment (Davis and Till von Wachter 2011). A wide body of research has shown that individuals who are laid off from their jobs (often referred to as displaced workers) frequently experience a prolonged period of unemployment after which they are forced to accept positions that offer lower pay than their prior job, have less job security and promotion potential, and frequently do not provide benefits (Brand 2006, Farber 2003, Fallick 1996, Keltzer 1998).

Recent macro-economic trends have contributed to the issues facing displaced workers in the United States. In early 2009, the United States unemployment rate rose above $8.5 \%$ for the first time in more than 25 years; it has remained over $8 \%$ ever since (United States Bureau of Labor Statistics). Not surprisingly, macro-economic conditions are inextricably intertwined with the labor market outcomes for displaced workers. Individuals who lose their jobs during periods of high unemployment are more likely to remain unemployed for a longer period of time and are less likely to recover their pre-displacement wages (Von Wachter, Song and Manchester 2009, Davis and Till von Wachter 2011).

\subsection{Job Loss and Health}

The potential negative consequences of job loss extend beyond the financial and labor market outcomes discussed above. Recently, researchers have paid particular attention to the consequences that job loss can have on an individual's physical health. The stress of looking for work and the feelings of shame often associated with being out of work can have negative consequences for mental health which may translate into declines in physical health as well (Newman 1988, Uchitelle 2006). In addition, many of the long-term economic outcomes that frequently result from job displacement, in particular the decline in earnings, are directly associated with health status (McWilliams et al 2007, Baker et al 2001, Benzeval and Judge 2001, Herd et al 2007, Berry 2007).

Recent research has supported the premise that job loss has negative consequences for health that remain even after the individual has found new employment. Using data from 19992003, Strully (2009a), found job loss due to plant/business closures, layoffs, or discharge (firing) during the previous two years was associated with worse self-rated health outcomes relative to the continuously employed, as well as an increased probability of developing at least one of a series of health conditions including heart disease, hypertension, diabetes and arthritis. Burgard, Brand and House (2007) found that individuals who experienced job displacement due to plant/business closures, downsizing and relocations between 1975 and 1993 had slightly lower self-rated health compared to those who did not suffer an involuntary job loss during this period. The long time frame of the study suggests that the health consequences of job loss may be permanent, or at least remain for an extended period of time. In addition, the fact that both Strully (2009a) and Burgard, Brand and House (2007) found significant associations using measures of job loss (e.g. plant closings, downsizing, layoffs) that are fairly exogenous to the potential work and health behavior characteristics of 
the employee, suggests that the relationship between job loss and health is not a spurious one. Research by Gallo (2006), using a wider definition of involuntary job loss but incorporating instrumental variable techniques, also supports the conclusion that the relationship between job loss and health is real and significant.

\subsection{Macroeconomic Conditions and Health}

In contrast, much of the research on the relationship between macro-level economic conditions and individual or aggregate population level health has suggested that a countercyclical relationship exists between the two. Several studies using data from the United States and Germany between 1970-2000 have found a counter-cyclical relationship between national unemployment rates and the mortality rate (Ruhm 2000, Neumayer 2004) as well as an inverse relationship between state unemployment rates and the likelihood that individuals will have an acute or chronic medical condition (Ruhm 2003). Several diverse theories have been proposed for these counter cyclical patterns including increased traffic accidents, higher prevalence of smoking and a decrease in time spent exercising in periods of low unemployment (Xu 2013, Burgard, Aikshire and Kalova 2013). Research on macroeconomic conditions and health are not entirely consistent however. For instance, Gerdtham and Johannesson (2005), and Blomgren and Valkonen (2007) found that in Sweden and Finland, higher job displacement and unemployment rates were associated with an increased probability of mortality.

\subsection{Moderating Influence of Macroeconomic Conditions on the Consequences of Job Loss for Health}

To summarize, individual job loss appears to have a negative impact on individual health although paradoxically, when macro-economic conditions worsen, the health of the population may tend to improve, perhaps particularly in the United States. This is in spite of the fact that the impact of individual job loss on wages, unemployment duration and other economic consequences worsen when the job loss occurs in recessionary periods. Given these somewhat conflicting findings, an interesting question is how might macroeconomic conditions moderate the impact of job loss on health?

This could work in two ways. First, the counter cyclical effect of macro-economic conditions on health might ameliorate the impact of displacement. Second, given that a) individual economic outcomes following displacement are worse when the displacement occurs when the economy is poor, and b) these economic outcomes are known to influence health, we might expect that displacement during difficult economic times would translate into worse health outcomes. The aforementioned two situations are not mutually exclusive. The first of these possibilities takes into account macro-economic conditions at any time we might assess health following displacement. It is worth remembering that the impact of displacement on health is not necessarily immediate and effects have been shown to last for a long time (Burgard, Brand and House 2007). The second possibility focuses on macroeconomic conditions specific to the time of displacement, as this is the point at which an individual must find a new job. This paper will focus on evaluating the second possibility. 
For two reasons, it is also quite possible that a moderating effect of macro-economic conditions may level off when the displacement occurs during very weak economic periods. First, while the negative effect of job loss on health may be serious, it is unlikely to increase infinitely along with a deteriorating economy. Second, when displacement is a common occurrence, the shame associated with job loss may be ameliorated. The feeling of support due to other's being in the same condition may somewhat counteract the negative economic effects.

Research to date has not directly addressed the moderating effect of macroeconomic conditions at the time of displacement on the relationship between job loss and health, although a few researchers have explored the relationship between the unemployment rate, an individual's employment status and health or mortality, again with somewhat mixed results. Blomgren and Valkonen (2007) found that the cyclical relationship (in their study) between the unemployment rate and mortality was stronger for the long term unemployed, and Ahs and Westerling (2005) found that the positive relationship between being employed and self-rated health is stronger in periods of high unemployment. However, using mortality as an outcome, Martikainen and Valkonen (1996) found the reverse to be true.

\subsection{Moderating Influences of Education on the Consequences of Job Loss for Health}

The educational attainment of the displaced worker might also moderate the impact of job loss on health. While there is no consistent relationship between educational attainment and labor market outcomes following job loss (Farber 2003, Helwig 2004, Koeber and Wright 2001), the positive relationship between educational attainment and health across the life course has been well documented (Adler and Rehkopf 2008, Mirowsky and Ross 2003, Herd et al 2007). The link between educational attainment and better health is a result of many factors including greater access to financial resources as well increased health-related knowledge among the well educated. The direction of the moderating effect of education on the relationship between job loss and health is difficult to predict. Individuals with less education are likely to have fewer resources to safeguard their health following job loss, and may therefore suffer worse consequences. However, individuals with higher education and better health at the outset may have 'further to fall' in terms of their health following job loss and so could experience greater negative consequences than those with less education.

This paper therefore seeks to contribute to existing knowledge by examining the extent to which the impact of worker displacement on health outcomes is moderated by two distinct factors: economic conditions at the time of displacement and the educational attainment of the displaced worker.

Hypothesis 1 The long-term effect of job loss on health will be greater when the displacement occurs during a period of high unemployment. However, this effect may level off at very high unemployment rates.

Hypothesis 2 The educational attainment of the displaced worker will moderate the consequences of displacement on health. Here, the direction of the moderating effect is more difficult to predict. 


\section{Data and Methods}

\subsection{Data Source and Sample}

The data source is the Wisconsin Longitudinal Study (WLS). This panel survey has followed a cohort of 10,317 Wisconsin high school graduates from their year of graduation (1957) through 2004. The WLS includes detailed employment histories for each respondent between 1975 and 2004, including the reason the individual left each job reported during that time period, as well as measures of self-rated health in 1992-3 and 2004. The lengthy duration of the employment history data permits assessment of long-term impacts of job loss on health. Unlike the National Longitudinal Survey of Youth, health is measured at multiple points in time in the WLS. Unlike the Panel Study of Income Dynamics, which contains information on both job loss and health, the WLS distinguishes between types of job loss which may be related to the characteristics or behavior of the employee (e.g. firing) from "no fault' job losses such as downsizing and mass layoffs. (The PSID does not distinguish between job loss due to downsizing/layoffs and firing). This distinction is critical for developing a measure of job loss that is exogenous to characteristics that may also impact health outcomes. WLS response rates have ranged between 70-90\% since 1975. In addition, there are no known biases or respondent characteristics associated with attrition in the WLS over time (Burgard, Brand and House 2007). However, one potential issue is attrition due to death. By $1992-3,5 \%$ of the original sample had died; as of 2004 this had increased to $12 \%$. These individuals likely had poor health. If displacement impacts both mortality and health, estimates for the impact of displacement on health are likely more conservative due to attrition because of mortality.

The main limitation of the WLS is that the sample is quite homogeneous. According to the Wisconsin Longitudinal Study handbook 'only a handful' of respondents were of an ethnic group other than non-Hispanic white. In addition, 75\% of the respondents were born in 1939 and all have at least a high school degree. All of these sample characteristics potentially limit the generalizability of the findings. Finally, the sample is basically a state sample as all respondents grew up in Wisconsin and more than 70\% remained there as of 2004. However, on some key characteristics, such as marital status and at least some measures of educational attainment, the WLS sample in 1992-3 is comparable to white, high school educated respondents of similar age from the National Health Interview Survey in $1993^{1}$. In spite of these limitations, the WLS is the best survey available to examine the long-term impacts of 'exogenous' job loss on health and has been used in prior research exploring this topic (Burgard, Brand and House 2009) as well as more than 300 journal articles on a variety of other topics.

\footnotetext{
${ }^{1}$ I compared the educational attainment and marital status of WLS respondents in 1993 with a sample of white respondents born in 1939 with at least a bachelor's degree from the National Health Interview Survey 1993. The marital statuses of the two groups are quite similar; $80 \%$ of the NHIS sample and $83 \%$ of the WLS sample were married while $5 \%$ of the NHS sample and $4 \%$ of the WLS sample had never been married, leaving $15 \%$ of the NHIS sample and $13 \%$ of the WLS sample as widowed, divorced or separated. The educational attainment of the WLS sample is slightly lower than the NHIS sample. While $29 \%$ of the NHIS and $26 \%$ of the WLS sample hold bachelor's degrees, $24 \%$ of the NHIS sample have attended some college while only $13 \%$ of the WLS sample fall into this group. I believe the educational differences are less problematic due to the fact that I include education as a moderating variable in my models; thus estimating separate effects of displacement for each group. The only possible issue with generality would be if there is an undetected three way interaction between education, macroeconomic conditions and displacement.
} 
The sample consists of respondents who answered the self-rated health question in either 1992-3 or 2004. This sample thus includes measurements at up to two time points for each individual, with the unit of analysis being the person-year. I also restricted the sample to respondents who had worked at least some point between 1975 and 2004 and who were not missing data on the reason why they had left any job since 1975. A small number of observations were also excluded due to missing data on other covariates used in the analysis $^{2}$. The final sample consisted of 11566 person-year observations.

\subsection{Measures}

The variables used are presented in Table 1 and descriptive statistics for these variables are presented in Table 2.

Health-Health outcomes are measured by self-rated overall health. WLS respondents were asked to rate their health on a 5 point scale ranging from very poor to excellent. Health was measured twice: in 1992-3, when the respondents were in their early 50s, and in 2004 when they were in their early 60s. A significant body of literature (Ferraro and Kelly-Moore 2001, Fritjers and Ulker 2007, Idler and Benyamini 1997) has demonstrated strong links between self-rated health and a variety of objective health measures such as medical conditions and mortality. For this reason, self-rated health is widely used in social science research that examines the links between unemployment, income, and health outcomes.

Worker Displacement and other Types of Job Loss-It is important to use a measure of job loss that is exogenous to health related behaviors, prior health conditions and other unobserved characteristics which might also influence health outcomes. I thus define worker displacement (sometimes referred to as simply displacement) as the involuntary loss of a job that is not related to the health or the work-related characteristics, skills or behavior of the employee. I restrict worker displacement to job losses which occurred because the employing company closed, downsized (implemented permanent layoffs) or relocated. These three outcomes are collapsed into one category the WLS. I distinguish between displacement and early or forced retirement (referred to as retirement displacement), as the former may include a benefits package (such as a pension) that would alleviate the impact on health. I also include variables to control for the impact of other types of involuntary job loss such as being fired and the failure of a self-owned business (referred to as business failure). Because loss of a temporary or seasonal job is a different experience from being displaced from a long term position, I have included a separate variable for involuntary loss of temporary/seasonal jobs. Finally, I include a variable for voluntarily or involuntarily leaving a job for health reasons as such job separations are clearly not exogenous vis a vis health.

Macro-Economic Conditions in the year of displacement-The concept I examine here is how persons who are displaced in periods of high unemployment might fare worse (in terms of health) than individuals displaced under better economic conditions. The idea is

${ }^{2}$ Observations were excluded for the following reasons: Not working at all between 1975 and 2004 (474); missing data on: self-rated health (150); reason for leaving job (1250); year a job ended (12); other covariates (88). I used multiple imputation for earnings (missing for $8-10 \%$ of the sample). 
that the economic conditions when an individual is displaced contribute to the conditions of the displacement itself. The economic conditions at the time of displacement are most relevant as this is when displaced individuals conduct their search for a new job, which has implications for future earnings, health insurance status and other factors which may ultimately influence their health. I therefore include a variable measuring the unemployment rate in the year of displacement for each respondent who has experienced displacement. This variable is a simple index based on two steps using two measurements: Step 1: if the respondent has not been displaced assign a value of 0; Step 2: if the respondent has been displaced assign the value of the unemployment rate in the year they were displaced. Respondents who were not displaced have a value of 0 because they have no 'year of displacement' and hence no unemployment rate in the year of displacement. In addition, assigning them a value of 0 allows for the interpretation of the variable described in the following paragraph.

This variable can be understood as an adjustment to the functional form of the variable measuring displacement that was described on the previous page. The $0 / 1$ variable 'displacement', which indicates whether the respondent has been displaced, measures the 'baseline' effect of displacement. The variable measuring the unemployment rate in the year of displacement allows for estimation of an additional effect which varies according to the economic conditions (unemployment rate) at the time of displacement. The sum of the two variables (each multiplied by the respective coefficient) is the total effect of displacement for a specific individual. The impact of both variables are measured relative to the respondents who are not displaced, who have a value of 0 for both variables, as they are by definition not impacted by displacement (whether the unemployment rate at the time of displacement is considered or not). The variable 'unemployment rate in year of displacement' thus allows us to assess the extent that the unemployment rate in the year of displacement contributes to the total impact of displacement on health, or in other words, whether the impact of displacement is moderated by the Wisconsin unemployment rate in the year of displacement.

Because more than $70 \%$ of the respondents have been living in Wisconsin at each wave of data collection, with no more than 3\% living in any other single state, I use the Wisconsin unemployment rate in the year of displacement for each respondent who was displaced. Over the 30 years for which employment histories were collected (1975-2004), the annual Wisconsin unemployment rate ranged from 3.1 to 10.3. In order to allow for the tapering of the moderating effect at very high unemployment rates, I include a dummy variable which has a value of 1 when the Wisconsin unemployment rate was greater than 10 in the year in which the respondent was displaced. This variable also has a value of 0 when the respondent has not been displaced.

NOTE: This variable is not intended to measure the general economic conditions in the year health was assessed, which would apply to all respondents. While macroeconomic conditions may indeed also have an independent effect on health, it is not necessary to include a variable for the impact of general economic conditions (for the population at large) on health for this sample. Such a variable would be measured in the time that health was assessed: 1992-3 (late 1992 and early 1993) and 2004. The Wisconsin unemployment rate 
was 5.0 in both of these time periods. Therefore that variable would have no variance for this sample. Thus the effect of general macro-economic conditions on health is controlled for by the sample itself.

Moderating Effect of Educational Attainment-I include a series of dummy variables to distinguish if the respondent had a high school degree only, had attended some college (less than a bachelor's degree), or had a bachelor's degree or higher. To capture the moderating impact of education, I include interaction terms between job displacement and educational attainment as measured by the aforementioned categories. Because both education and displacement are categorical variables represented by a series of $0 / 1$ variables, displacement*bachelors degree has a value of 1 if the person experiences displacement and has a bachelor's degree and 0 otherwise. Displacement*some college is equal to 1 if the person experiences displacement and has attended some college (less than a bachelor's degree) and 0 otherwise. Education is a time invariant variable that was measured in 1975 when the great majority of the respondents were 36 years old. Therefore for most respondents, educational attainment is unlikely to change after this point in time.

Additional Covariates-I also include in all models a set of standard covariates typically used in models to estimate health outcomes (gender, age, marital status, family economic background in 1957). Marital status is measured in the year in which health was measured. While this may result in some selection bias for the marital status coefficient, greater bias in terms of the effect of displacement on health would result from excluding the variable. In addition, I include several variables often included in models used to estimate the probability of displacement, but which also may impact health. These are pre-displacement earnings, experience in the manufacturing, mining and construction industries (which have particularly high displacement rates and may expose workers to hazardous chemicals and other physical risks) and a full set of controls for work experience in the standard set of occupational classifications. All employment variables except pre-displacement earnings were measured in the year in which health was measured; pre-displacement earnings were measured in 1975 as all displacements occurred after this date. Because the WLS sample is nearly all non-Hispanic white, variables for race and ethnicity are not included in the public use data set. Therefore I do not include these variables in my models.

We see from Table 2 that $17 \%$ of the sample has experienced displacement. Approximately half of the sample is male. The sample is more educated than the U.S. population born in the late 1930's; one quarter of the sample have at least a bachelor's degree and an additional $14 \%$ have at least some college. Not surprisingly then, nearly a third of the sample having work experience in professional/technical managerial and administrative/clerical positions. Blue collar occupations are also well represented; nearly $30 \%$ of the sample has been employed in craft, operator or laborer positions. The average respondent earnings of $\$ 33,447$ is somewhat below the national average of $\$ 39,354$ for 2004 (Bureau of Labor Statistics).

\subsection{Analytic Strategy}

To estimate the impact of displacement on self-rated health and examine the moderating impact of unemployment rate, education level and age at displacement, I estimated two sets 
of models. The first set of models was estimated using ordered probit techniques. The second set of models was estimated using fixed effects methods in order to provide a stronger control for unobserved characteristics that might simultaneously influence displacement and health.

Ordered Probit Models-I used a series of three ordered probit models. The first ordered probit model included a variable for whether the respondent had been displaced as well as the full set of demographic, family background, and employment context controls, and the other types of involuntary job loss described in Table 2. The additional ordered probit models added variables to assess the moderating effects of educational attainment of the displaced worker (models 2-3), and the Wisconsin unemployment rate in the year of displacement (model 3). Because my sample includes two repeated measures of the same individuals over time (in 1992-3 and 2004), I used adjusted standard errors for the parameter estimates, which correct for the presence of correlated errors within respondents $(\text { Hsiao 2003) })^{3}$.

Fixed Effects Models-The ordered probit models operate under the assumption that displacement is an exogenous variable vis a vis the health of respondents at the time of displacement. The displacement variable was therefore constructed to be as exogenous as possible, by restricting displacement to company closings, downsizings and relocations. However, we can not rule out the possibility that respondents who were displaced were more likely to have unobserved characteristics not captured by the model that might influence their health. This is not an unreasonable concern, as there is evidence that when deciding whom to lay off, employers take into account work productivity and other work related characteristics (Romm 1995, McCune 1988). These may in turn be related to minor health conditions or other personal characteristics or behaviors that might influence health. It is also possible that respondents who select jobs in industries that have high displacement rates may be more likely to have unobserved characteristics associated with poorer health. Finally, the correlation between these unobserved characteristics and the probability of job loss may depend on both the individual's educational attainment and the macro-economic conditions at the time of job loss, potentially confounding the moderating effects. In order to address these issues, I also estimated a series of fixed effects models.

The fixed effects models make use of the panel nature of the data to control for time invariant unobserved characteristics not otherwise captured by the model. There are many ways to mathematically represent a fixed effects model, but one way to conceptualize it is that a dummy variable is added to the model for each individual. These dummy variables absorb the effect of unobserved characteristics that are fixed for that respondent over the span of time during which data is collected ${ }^{4}$. Because it is not possible to estimate a fixed effects model for ordered probit with two time periods, I estimated linear fixed effects

\footnotetext{
${ }^{3}$ I do not present the ordered probit thresholds/cutpoints in coefficient tables.

${ }^{4} \mathrm{~A}$ general linear model for panel data can be represented: $\mathrm{Y}_{\mathrm{ti}}=\mathrm{X}_{\mathrm{ti}} \beta+\mu_{\mathrm{i}}+\varepsilon_{\mathrm{ti}} ; \mathrm{Y}_{\mathrm{ti}}=$ continuous measure of health from 1 to $5 ; \mu_{\mathrm{i}}=$ time invariant unobserved characteristics. The fixed effects model absorbs these characteristics into a dummy variable for each respondent: $\mathrm{Y}_{\mathrm{ti}}=\mathrm{X}_{\mathrm{ti}} \beta+\Sigma \mathrm{a}_{\mathrm{i}}+\varepsilon_{\mathrm{ti}}$.
} 
models. This is a generally valid approach for models using self-rated health as an outcome, because a self-rating of health on a 1-5 scale is approximately linear in its construction ${ }^{5}$.

In interpreting the fixed effects models, a few things are important to note. First, the sample for the fixed effects model includes only respondents who completed the survey in both 1992-1993 and 2004. This due to the mathematical construction of a fixed effects model, whereby respondents with only one observation point will drop out automatically. The sample of person-year observations for the fixed effects models is 9682.

Secondly, in a fixed effects model, all time invariant characteristics (education, gender) are absorbed into the fixed effect and are not separately estimated. Because the outcome variable (health) was measured in 1992-3 and 2004, all displacements prior to 1992-3 are treated as a time invariant characteristic, because they do not 'change' (occur) between 1992-3 and 2004. Therefore, in the fixed effects model, 'displacement' includes only displacements between 1992-3 and 2004. Earlier displacements are controlled for, but their impact on health is not evaluated ${ }^{6}$. The same is true for other types of involuntary job loss. The impact of other employment related variables such as occupation and industry also are restricted to respondent experiences between 1992-3 and 2004. For instance, occupation and industry variables are recoded from 'ever worked in this occupation/industry' to 'worked in this occupation/industry at some point between 1993-2004'.

The progression of the fixed effects models parallels that of the ordered probit models with the first model including a variable for displacement as well as all time-varying covariates. The additional fixed effects models added variables to assess the moderating effects of educational attainment of the displaced worker and the Wisconsin unemployment rate in the year of displacement. Because the fixed effects models only estimate the impact of displacements between 1992-3 and 2004, the number of displacements is much smaller than in the ordered probit models. For instance, there are only 469 total displacements, 95 of which happen to respondents with a bachelor's degree. Therefore the fixed effects models lack statistical power and subsequently results for the moderating variables are sensitive to which value is used as the reference category.

\section{Results}

\subsection{Ordered Probit and Fixed Effects Results}

Results from the initial ordered probit model (Model 1) is presented in in Table 3. The covariates are statistically significant and in the expected directions. Being younger (approximately 54 as opposed to 65), female, married and having additional education beyond high school, having higher earnings in 1975, and growing up in a family with higher SES are all associated with a higher probability of being in 'better health'. Working in manufacturing, mining and construction are associated with a lower probability of being in

\footnotetext{
${ }^{5}$ I also estimated Model 3 using linear regression. The sign and significance of the coefficients are comparable to Model 3. Results available upon request.

6 If a respondent was displaced more than once, I used the latest displacement; therefore these displacements are included in the fixed effects models if they occurred in 1993 or later.
} 
'better health', whereas some occupations (professional/technical, managerial and administrative) serve as a protective factor vis a vis health.

Not surprisingly, we also see in Model 1, Table 3 that experiencing a temporary or seasonal job loss and leaving a job for health reasons are significantly associated with a lower probability of being in 'better health'. The coefficients for business failure and a retirement displacement are negative, although not statistically significant. The number of business failures is very low $(<65)$. In addition, only 88 respondents experienced retirement displacement without also experiencing regular displacement. Therefore, the model lacks adequate power to accurately assess the impact of business failure and retirement displacement.

The initial fixed effects model (Model 4) is presented in Table 4. We see from Model 1 (Table 3) and Model 4 (Table 4) that experiencing displacement is significantly associated with a lower probability of being in 'better health' (ordered probit) and has a significant negative impact on self-rated health (fixed effects). This indicates that displacements occurring between ages 54 and 65 have a genuine negative impact on health that is not simply due to unobserved characteristics of those who were displaced. The similarity of the findings between the two models also suggest that there is not a selection into job displacement by less healthy individuals. This is confirmed by results from a model estimating the impact of self-rated health in 1993 on the probability of being displaced between 1993 and 2004 (shown in Table 9 in the Appendix); the coefficient for self-rated health is not significant. In contrast, as also shown in Table 9, health status in 1993 does significantly impact the probability of being fired or leaving a job for health reasons between 1993-2004. It should also be noted that the health of the WLS respondents in 1993 and 2004 is very similar to the health of respondents from the National Health Interview Surveys of comparable age, education and race in the same years. Details are presented in Table 10 in the Appendix.

I estimated two additional ordered probit and fixed effects models including variables to assess the moderating effects of education level and macro-economic context. The key results from ordered probit Models 1-3 are presented in Table 5; fixed effects models 4-6 are in Table 6. All models include the entire set of variables in Table 3 (ordered probit) or Table 4 (fixed effects), including the variables for other types of job loss. However, the magnitude and size of the coefficients for the additional covariates are nearly indistinguishable among models 1-3 and models 4-6. Therefore I have not presented these coefficients in Tables 5 and 6 . These results are available upon request.

In both Models 2 and 3 (Table 5), the interaction term between displacement and having at least a bachelor's degree is negative and statistically significant, indicating that any negative impacts of displacement on health are magnified for the respondents with the most education. The interaction term for displacement and having some college education is not statistically significant. However, there are not many respondents in the displaced and some college education category $(n=263)$, therefore the model has minimal statistical power vis a vis this group. The coefficients for the interactions between 1) displacement and bachelor's 
degree and 2) displacement and some college are jointly statistically significant in both Model $2\left(X^{2}(\mathrm{df}=2)=6.12 ; \mathrm{p}=.047\right)$ and Model $3\left(X^{2}(\mathrm{df}=2)=6.81 ; \mathrm{p}=.033\right)$.

Theoretically, the negative impact of displacement may be stronger for bachelor's degree holders because respondents with some or no college education are more likely to die rather than remain alive in poor health. However, in 1993/2004, the percentage of former survey participants known to be dead was 3\%/10\% (bachelor's degree); 4\%/10\% (some college education); $4 \% / 12 \%$ (no college education). The differences in mortality rates among the educational groups are small and unlikely explain the model results.

In fixed effects Model 5 (Table 6), which adds interaction terms for 1) displacement and some college and 2) displacement and a bachelor's degree, neither the main effect of displacement nor the interaction terms are significant. The interaction terms between displacement and education are also not significant in Model 6 (Table 6), which also adds the moderating effect of unemployment rate in the year of displacement. Given that the interaction term between displacement and having a bachelors' degree is not significant in Models 5 and 6, the results for the moderating effect of education are inconclusive at best; we can not rule out the possibility that the findings from the ordered probit models were spurious ${ }^{7}$.

Model 3 (ordered probit; Table 5) and Model 6 (fixed effects; Table 6) each include a variable for the Wisconsin unemployment rate in the year a respondent was displaced, which has a value of 0 for respondents who were never displaced. This variable also assesses the impact of displacement, but allows the effect to vary according to the Wisconsin unemployment rate in the year of displacement. Due to the inclusion of the variable measuring Wisconsin unemployment rate in the year of displacement, the coefficient of the variable displacement in these models is the effect of displacement when the Wisconsin unemployment rate is 0 (and the respondent does not have any college education), and is thus not particularly meaningful in and of itself. The results from Models 3 and 6 (Tables 5 and 6 respectively) indicate that the variable for Wisconsin unemployment rate in the year of displacement is statistically significant, with the negative impact on health growing stronger as the Wisconsin unemployment rate in the year of displacement increases. This indicates that the Wisconsin unemployment rate in the year of displacement contributes significantly to the total impact of displacement, and thus the total impact of displacement must be interpreted conditional upon the unemployment rate at the time of displacement.

For example, based on results from Model 3 (Table 5), if a non college educated respondent was displaced when the Wisconsin unemployment rate is 5.0, the total (combined) coefficient for the impact of displacement is: $\left[\beta_{\text {displaced }}+\right.$ $\left(\beta_{\text {Wisconsin unemployment rate in year of displacement }}{ }^{*}\right.$ Wisconsin unemployment rate in year of

\footnotetext{
${ }^{7}$ The fact that both the main effect of displacement and the interaction terms with bachelor's degree and some college are not significant in Models 5 and 6 in Table 6 does not mean that there is no significant effect of displacement in the fixed effects models. In fact we saw that there is a significant negative effect of displacement in Model 4, Table 6. Because the number of total displacements (469) and displacements for those with a bachelor's degree (95) is small for the fixed effects models, the results are sensitive to which educational group is chosen as the reference category. If instead, bachelor's degree recipients were used as the reference category in Model 5, the main effect of displacement $(-0.149 ; \mathrm{SE}=.071)$ would be significant at $\mathrm{p}<.05$. Nevertheless, there is no significant interaction between education and displacement in the fixed effects models.
} 
displacement $)]=[0.227+(-0.044 * 5.0)]$. Due to the moderating effects of education, for a respondent who has a bachelor's degree who is displaced when the Wisconsin Unemployment Rate is 5.0, the total displacement coefficient is: $\left[\beta_{\text {displaced }}+\right.$ $\beta_{\text {displaced and bachelor's degree }}+\left(\beta_{\text {Wisconsin unemployment rate in year of displacement }} *\right.$ Wisconsin unemployment rate in year of displacement $)]=[0.227-0.198+(-0.044 * 5.0)]$. Using the coefficients from Model 3 (Table 5), Figure 1 shows the total coefficients for the impact of displacement on health for Wisconsin unemployment rates in the year of displacement that range between 3 and 10. Each point on the graph shows the total impact of displacement (e.g. the combined coefficient) for a specific unemployment rate at the time of displacement for persons with different levels of education.

As Figure 1 illustrates, for those who have not attended college, the impact of displacement on health is negative when the unemployment rate in the year of displacement is at least approximately 5.2. This is statistically significant $(\mathrm{p}<=.05)$ when the unemployment rate in the year of displacement is between 7.0 and $10^{8}$. Thus when the unemployment rate in the year of displacement is below 7.0, the impact of job loss on health is not statistically significant for respondents who have not attended college. While displacements that occur when the unemployment rate is less than 5.2 appear to have a 'positive' effect on health, this effect is not statistically significant, even at (hypothetical) unemployment rates as low as 0.1 . For those with at least a bachelor's degree, the impact of displacement on health is negative for the entire range of unemployment rates (in the year of displacement) between 3 and 10 and is significant when the unemployment rate (in the year of displacement) is between 4.3 and 10.0 .

Using results from fixed effects Model 6 (Table 6), Figure 2 shows the impact of displacement at the range of Wisconsin unemployment rates (in the year of displacement) that occurred between 1992 and 2004. Because the interaction term between displacement and having a bachelor's degree (or having some college) is not statistically significant, the impact shown in Figure 2 applies to all educational levels.

Figure 2 shows that the impact of displacement on health is negative when the unemployment rate in the year of displacement is at least approximately 3.6. This is statistically significant when the unemployment rate in the year of displacement is at least 4.6 $6^{9}$. When the unemployment rate in the year of displacement is less than 3.6, the impact of displacement on health is 'positive', but it is not statistically significant for (hypothetical) unemployment rates rate in the year of displacement as low as 0.5. Based on the results from Model 6 (Table 6), a respondent who is displaced when the Wisconsin unemployment rate is 6.0 has a predicted value of self-rate health (on a 5 point scale) that is .21 lower than a

\footnotetext{
${ }^{8}$ The statistical significance is the statistical significance of the combined coefficient:

If no college: $\left[\beta_{\text {displaced }}+(\beta\right.$ Wisconsin unemployment rate in year of displacement $*$ Wisconsin unemployment rate in year of displacement)]

If bachelor's degree: $[\beta$ displaced $+\beta$ displaced and bachelor's degree $+(\beta$ Wisconsin unemployment rate in year of displacement *Wisconsin unemployment rate in year of displacement)]

${ }^{9}$ The statistical significance is the statistical significance of the combined coefficient For all education levels: $\left[\beta\right.$ displaced $+\left(\beta\right.$ Wisconsin unemployment rate in year of displacement ${ }^{*}$ Wisconsin unemployment rate in year of displacement)]
} 
similar respondent who has not been displaced. A respondent displaced when the Wisconsin unemployment rate is 7.0 has a predicted value of self-rated health that is .30 lower than a similar respondent who was not displaced.

\subsection{Additional Interpretation of Ordered Probit Results}

In order to better to the interpret the magnitude of results from the ordered probit Model 3 (Table 5), it is useful to examine the impact of job loss under varying macro-economic conditions and educational attainment levels on the predicted probabilities of having specific levels of health. I therefore conducted a series of microsimulations to estimate the predicted probability of having each self-rated health value ( $1=$ very poor health, $2=$ poor health, $3=$ fair health, $4=$ good health, $5=$ excellent health), under the conditions of not being displaced, as well as displaced when the Wisconsin unemployment rates were 5.0 and 8.0. Separate simulations were calculated for respondents with a high school diploma (no college) and those with a bachelor's degree or higher. The results are shown in Figure 3. I excluded respondents with some college, as the interaction term for displacement with some college education is sizeable but not statistically significant, making interpretations difficult for this group. Further discussion of the microsimulation method is in end note $9^{10}$.

Figure 3 shows that for respondents with no college education, there is no discernible impact on health of being displaced when the Wisconsin unemployment rate in the year of displacement is 5.0. However, when the Wisconsin unemployment rate in the year of displacement is 8.0, the simulated probability of being in excellent health declines from $21 \%$ for those who are not displaced to $17 \%$ for those displaced. Similarly, the probability of being in fair health increases from $13 \%$ to $16 \%$. For respondents who lack a college degree, the impact of displacement and the moderating effect of the unemployment rate mainly impact the distribution of self-rated health in terms of the proportion of respondents in excellent and fair health. There is little impact on the proportion of respondents with good health, poor health and very poor health, in part because the last two categories include a minimal proportion of respondents.

We also see from Figure 3 that respondents with a bachelor's degree who are displaced when the Wisconsin unemployment rate is 5.0 see their simulated probability of being in excellent health decrease by a nearly a quarter (36\% to 29\%) compared to college educated respondents who were not displaced. When the unemployment rate in the year of displacement is 8.0, the simulated probability of being in excellent health falls even further: to $25 \%$. When no displacement has occurred, respondents with a bachelor's degree have a simulated probability of being in excellent health that is 15 percentage points higher than those with no college education ( $36 \%$ to $21 \%$ ). When displacement occurs when the Wisconsin unemployment rate is 8.0 , this gap narrows to 8 percentage points ( $25 \%$ to $17 \%$ ).

\footnotetext{
${ }^{10}$ The micro-simulated probabilities were calculated as follows: Using the coefficients from Model 3, predicted probabilities (of having each self-rated health value) for each respondent were simulated, first assuming the respondent was not displaced, then assuming the respondent was displaced when the Wisconsin unemployment rates were 5.0 and 8.0. Each respondent retained their own value for each of the other covariates in each simulation. The probability of having each self-rated health value under the specific simulated condition was then averaged across respondents within the three educational levels: high school diploma (no college), some college, bachelor's degree or higher. The average simulated probabilities of having each level of self-rated health are shown in Figure 2. All variables are included in the simulation whether the coefficient was statistically significant or not. The coefficient is the best estimate of the parameter value and it is unlikely to truly be 0 .
} 
Therefore, by being displaced in a period of high unemployment, bachelor's degree holders lose approximately nearly $50 \%$ of the 'health returns' (in terms of the probability of being in excellent health) to their college education.

For bachelor's degree holders, the impact of job loss on health and the moderating effect of the unemployment rate have the strongest effect on the proportion of respondents who report excellent health. As the unemployment rate in the year of displacement increases, the declines in self-reported excellent health are correspond to smaller increases in the portion of respondents reporting both good and fair self-rated health. As for respondents with no college education, there is little impact on the proportion of respondents with poor health and very poor health, as these two categories include a minimal proportion of respondents.

\subsection{The Role of the Duration of Time Between Displacement and Health Assessment}

In this analysis, displacement may occur from anywhere between 1 month to nearly 30 years prior to the self-assessment of health. It is reasonable to ask whether one could expect the impact of job loss on health to continue over such a potentially long time frame. Therefore, I conducted additional analyses to explore whether the impact of job loss on health decreases over time. I estimated an additional variant of Model 3, including a variable for the duration of time between the most recent job loss and the time at which health was measured. The results from the key coefficients of this model are presented in Table 7 in the Appendix. The magnitude of the coefficient for the variable for duration of time between displacement and health measurement was very small and it was not statistically significant. In addition, inclusion of this variable had a negligible effect on the magnitude of the other coefficients in the model. These results are somewhat surprising as one might expect that the effect of a more recent job loss would have a stronger effect than a job loss many years prior, during the time since which intervening factors (e.g. a new job, unrelated life conditions which may improve or worsen health) may have been able to ameliorate the initial effect. However the effect of intervening factors such stress or loss of income on health may in fact accumulate over time. These two patterns may serve to effectively cancel each other thereby masking any moderating effect of time since job loss.

\subsection{Multiple Displacements and Health Assessment}

It is also reasonable to expect that the impact of multiple displacements on health might be more severe than the effect of a single displacement. Therefore, I also conducted analysis exploring the impact of multiple displacements. Because a very small number of respondents (38) experienced more than 2 displacements, I used one category to measure the existence of multiple displacements. Because very few respondents (37) experienced multiple displacements in the fixed effects sample, this analysis was only conducted for the ordered probit models. The results are shown in Table 8 in the Appendix. The coefficient for multiple displacements is negative but not statistically significant, suggesting that the primary impact of displacement on health occurs as a result of the first displacement. 


\section{Discussion and Conclusion}

The results from the ordered probit and fixed effects models suggest that the negative consequences of displacement for health are stronger when the respondent was displaced in a period of higher unemployment. In addition, displacement does not have negative health consequences for all individuals. Respondents who are displaced in a strong economy, especially those with less than a bachelor's degree, appear to suffer limited or no adverse health consequence. Based on the ordered probit models, degree, job loss has negative health consequences for individuals without a bachelor's degree who are displaced in a year in which the Wisconsin unemployment rate is at least 7.7 (Figure 1). Based on the fixed effects models, negative consequences of job loss for health occur at unemployment rates as low as 4.6 (Figure 2).

Several differences between the two models may account for these differences. First, the displacements captured by the fixed effects models occurred relatively late in the respondents' working careers: approximately ages 54-65. It is possible that job loss at older ages has more serious consequences for health and thus negative impacts show up at lower unemployment rates. Other unmeasured moderating factors such as the occupation or industry of displacement may also play a role.

Multiple factors may account for the finding that displacement has worse consequences when the job loss occurs at a point in time when unemployment is relatively high. Individuals displaced in a recessionary period when few job openings are available will likely spend a longer time out of work. They may also be more likely to be forced to eventually accept positions involving difficult conditions such as non-standard or especially long work hours (particularly if they wish to recoup their former earnings as much as possible). They may also accept positions that do not provide the rewards they desire, either in terms of material benefits (such as earnings) or in more intangible factors such as the characteristics of the position and the work environment. Being out of work for a long period of time may result in individuals being forced to spend their savings, leading to a decline in wealth. In addition, the sobering experience of searching for work during a recession may result in a permanent state of anxiety about the possibility of losing one's job; the feeling that if it happened once, it can happen again.

However, in another sense, the finding that economic conditions at the time of displacement are such a strong moderator of the impact of displacement on health is somewhat surprising. The WLS measures health up to 30 years after the respondent has experienced displacement. During the period of time during which the data was collected, the unemployment rate rose and fell several times. Economic theory would suggest that if respondents are displaced during a period of high unemployment, once the unemployment rate drops, they should be able to more easily find work. If they have been forced to accept a less desirable position in the interim, when economic conditions improve, they should be able to find a more suitable position.

The fact that economic conditions in the year of job loss continues to moderate the impact of displacement on health, even when health is measured after economic conditions improve, 
suggests otherwise. It may be that jobs are more 'sticky' than economic theory would suppose. Respondents forced to accept a position they did not really want may become 'stuck' in this job, unable for a variety of potential reasons to search for and find a more suitable job. More research needs to be done to investigate the factors that enable formerly displaced workers to move from one position to another subsequent to displacement. It is also possible that the health effects of displacement are themselves sticky. That is, even if job conditions improve, respondents may never fully recover from the adverse health impacts of being displaced during a recession. Future research might disentangle whether the permanent adverse health consequences of displacement are reinforced by a lengthy period of difficult working conditions or occur in spite of improved job characteristics over time.

The results also suggest that the negative consequences of displacement for health are stronger for respondents with a bachelor's degree or higher. However, since the final fixed effects model, which also accounted for macro-economic conditions, did not show a significant moderating effect of education, the evidence is not conclusive on this matter. It is possible that differences between the sample of displacements included in the two sets of models (ordered probit and fixed effects) may account for some of these differences. For instance, if displacement at later ages does produce worse consequences for all persons, this may override differences related to education. It should also be noted that a limitation of the analysis exploring the moderating effect of job loss on health is that the WLS respondents are a relatively well educated for their age cohort. In particular, none of the respondents have less than a high school diploma. Therefore this analysis does not allow us to examine the moderating impact of lacking a high school degree.

Nevertheless, when displacement occurs in time periods when the unemployment rate is relatively low, the impact of displacement on health appears to be a declining middle class rather than a declining working class story. The literature suggests that psychological mechanisms may be key in understanding the negative consequences of health for displaced workers with a college degree. Using data from the WLS through 1992-3, Brand (2006) found that among college education respondents, displacement was associated with a loss of job autonomy, job authority and occupational status. Katherine Newman (1988) has also written extensively on the psychological factors such as shame and loss of work related identity among displaced middle class workers. Further research might examine the role of job characteristics and psychological factors as intervening mechanisms between displacement and health, particularly as this impacts displaced workers with a bachelor's degree. This would dovetail nicely with the growing interest in the public health literature in the relationship between psychological stress and physical health, in particular the mediating role that psychological stress plays in physical health disparities by socio-economic status. Stress is believed to negatively impact physical health through what is referred to as the 'allostatic load': the body's inability to fully physically recover from stressful events (Adler and Rehkopf 2008, Seeman et al 2008).

One additional way in which displacement might lead to increased stress is if displaced workers are working longer hours in order to preserve their income as much as possible. Highly educated workers may also be likely to refuse less desirable positions to wait for a 
job they feel which is commensurate with their skills. While this may serve them well in the long term, it also might result in longer periods of unemployment following displacement and the associated greater anxiety and loss of wealth, similar to the experiences of all workers displaced during a recession.

To conclude, the fact that in the WLS sample health was assessed up to 30 years after displacement occurred suggests that the negative impact of displacement on health appears to be long-term or permanent, and to extend far beyond the initial period of unemployment. Long term factors such as the characteristics of post-displacement employment may be important. This is additional evidence in support of the notion that instead of just focusing on creating jobs for the displaced, we must focus on creating 'good jobs' that will provide job related identity and stability similar to that which respondents gained from predisplacement jobs an which allow respondents to recoup their former earnings (as much as possible) and provide health insurance and pension benefits.

\section{References}

Adler, Nancy; Rehkopf, David. United States Disparities in Health: Descriptions, Causes and Mechanisms. American Review of Public Health. 2008; 29:235-52.

Ahs, Annika; Westerling, Ragnar. Self-Rated Health in Relation to Employment Status During Periods of High and of Low Levels of Unemployment. European Journal of Public Health. 2005; 16(3):294304.

Allison, Paul. Fixed Effects Regression Models. Thousand Oaks, CA: SAGE Publications; 2009.

Baker, David; Sudano, Joseph; Albert, Jeffrey; Borawski, Elaine; Dor, Avi. Lack of Health Insurance and Decline in Overall Health in Late Middle Age. New England Journal of Medicine. 2001; 345(15):1106-1112. [PubMed: 11596591]

Benzeval, Michaela; Judge, Ken. Income and Health: The Time Dimension. Social Science and Medicine. 2001; 52:1371-90. [PubMed: 11286362]

Berry, Brent. Does Money Buy Better Health? Unpacking the Income to Health Association After Midlife. Health. 2007; 11:199-226. [PubMed: 17344272]

Blomgren, Jenni; Valkonen, Tapani. Characteristics of Urban Regions and All-Cause Mortality in Working-Age Population: Effects of Social Environment and Interactions with Individual Unemployment. Demographic Research. 2007; 17(5):109-134.

Brand, Jennie. The Effects of Job Displacement on Job Quality: Findings from the Wisconsin Longitudinal Study. Research in Social Stratification and Mobility. 2006; 24:275-98.

Burgard, Sarah; Ailshire, Jennifer; Kalousova, Lucie. The Great Recession and Health: People, Populations and Disparities. The Annals of the American Academy of Political and Social Science. 2013; 650:194-213.

Burgard, Sarah; Brand, Jennie; House, James. Toward a Better Estimation of the Effect of Job Loss on Health. Journal of Health and Social Behavior. 2007; 48:369-84. [PubMed: 18198685]

Davis, Steven; von Wachter, Till. Brookings Papers on Economic Activity. 2011. Recessions and the Costs of Job Loss.

Fallick, Bruce. A Review of the Recent Empirical Literature on Displaced Workers. Industrial and Labor Relations Review. 1996; 50(1):5-14.

Farber, Henry. National Bureau of Economic Research Working Paper No. 9707. Cambridge, MA: 2003. Job Loss in the United States 1981-2001.

Ferraro, Kenneth; Moore, Kelley. Self-Rated Health and Mortality Among Black and White Adults: Examining the Dynamic Evaluation Thesis. Journal of Gerontology. 2001; 56B(4):S195-S205.

Frijters, Paul; Ulker, Aydogan. Robustness in Health Research: Do Differences in Health Measures, Techniques and Time Frame Matter? Journal of Health Economics. 2008; 27:1626-1644. [PubMed: 18639357] 
Gallo, William; Teng, Hsun-Mei; Falba, Tracy; Kasl, Stanislav; Krumholz, Harlan; Bradley, Elizabeth. The Impact of Late Career Job Loss on Myocardial Infection and Stroke: A Ten Year Followup using the Health and Retirement Survey. Occupational and Environmental Medicine. 2006; 63:683-87. [PubMed: 16798871]

Gerdtham, Ulf-G.; Johannesson, Magnus. Business Cycles and Mortality: Results from Swedish Microdata. Social Science and Medicine. 2005; 60:205-18. [PubMed: 15482879]

Helwig, Ryan. Worker Displacement in 1999-2000. Monthly Labor Review. 2004 Jun.2004:54-68.

Hemstrom, Orjan. Explaining Differential Rates of Mortality Decline for Swedish Men and Women: A Time-Series Analysis, 1945-1992. Social Science and Medicine. 1999; 48:1759-77. [PubMed: 10405015]

Herd, Pamela; Goesling, Bryan; House, James. Socioeconomic Position and Health: The Differential Effects of Education vs. Income on the Onset vs. Progression of Health Problems. Journal of Health and Social Behavior. 2007; 48:223-238. [PubMed: 17982865]

Hsaio, Cheng. Analysis of Panel Data. New York, NY: Cambridge University Press; 2003.

Idler, Ellen; Benyamini, Yael. Self-Rated Health and Mortality: A Review of Twenty-Seven Community Studies. Journal of Health and Social Behavior. 1997; 38(1):21-37. [PubMed: 9097506]

Kalleberg, Arne. Good Jobs, Bad Jobs: The Rise of Polarized and Precarious Employment Systems in the United States, 1970s to 2000s. NY: Russell Sage Foundation; 2011.

Keltzer, Lori. Job Displacement. Journal of Economic Perspectives. 1998; 12:115-136.

Koeber, Charles; Wright, David. Wage Bias in Worker Displacement: How industrial Structure Shapes the Job Loss and Earnings Decline of Older American Workers. Journal of Socio-Economics. 2001; 30:343-352.

Martikainen, Pekka; Valkonen, Tapani. Excess Mortality of Unemployed Men and Women during a Period of Rapidly Increasing Unemployment. The Lancet. 1996; 348(9032):909-12.

McCune, Joseph; Beatty, Richard; Montagno, Raymond. Downsizing Practices in Manufacturing Firms. Human Resource Management. 1988; 27(2):145-161.

McWilliams, J Michael; Mara, Ellen E.; Zaslavsky, Alan; Ayanian, John. Health of Previously Uninsured Adults after Acquiring Medicare Coverage. Journal of the American Medical Association. 2007; 298(24):2886-2994. [PubMed: 18159058]

Mirowsky, John; Ross, Catherine. Education, Social Status and Health. New York: Aldine de Gruyter; 2003.

Newman, Katherine. Falling from Grace: Downward Mobility in the Age of Affluence. London, England: University of California Press; 1988.

Neumayer, Eric. Recessions Lower (Some) Mortality Rates: Evidence from Germany. Social Science and Medicine. 2004; 58:2037-47.

Romm, Stuart. Layoffs: Princtiples and Practices. In: Elster, Jon, editor. Local Justice in America. New York: NY: Russell Sage Foundation; 1995.

Ruhm, Christopher. Good Times Make You Sick. Journal of Health Economics. 2003; 23:637-58. [PubMed: 12842319]

Ruhm, Christopher. Are Recessions Good for Your Health? The Quarterly Journal of Economics. 2000; 115(2):617-650.

Seeman, Teresa; Merkin, Sharon; Crimmins, Eleen; Koretz, Brandon; Charette, Susan; Karlamangla, Arun. Education, Income and Ethnic Differences in Cumulative Biological Profiles in a National Sample of United States Adults: NHANES III (1988-1994). Social Science and Medicine. 2008; 66:72-87. [PubMed: 17920177]

Strully, Kate. Job Loss and Health in the United States Labor Market. Demography. 2009a; 46(2):221246. [PubMed: 21305391]

Strully, Kate. Racial-ethnic Disparities in Health and the Labor Market: Losing and Leaving Jobs. Social Science and Medicine. 2009b; 69:768-776. [PubMed: 19615805]

Uchitelle, Louis. The Disposable American: Layoffs and their Consequences. New York, NY: Alfred A Knopf; 2006. 
Von Wachter, Till; Song, Jae; Manchester, Joyce. Long-Term Earnings Losses due to Mass Layoffs During the 1982 Recession: An Analysis Using US Administrative Data from 1974 to 2004. NY: Columbia University; 2009.

Wisconsin Longitudinal Study. Wisconsin Longitudinal Study Handbook. 2006.

Xu, Xin. The Business Cycle and Health Behaviors. Social Science and Medicine. 2013; 77:126-36. [PubMed: 23219162]

\section{Appendix}

\section{Table 7}

Impact of Duration between Displacement and Measurement of Self-Rated Health (Ordered Probit Model)

\begin{tabular}{|lcl|}
\hline & \multicolumn{2}{c|}{ Model 7 } \\
\hline & $\underline{\text { Coefficient }}$ & $\underline{\text { Std. Err. }}$ \\
Displaced & 0.216 & $(.115)$ \\
Bachelor's Degree & $0.322^{* *}$ & $(.041)$ \\
Some College & $0.147^{* *}$ & $(.044)$ \\
Reference group: high school only & & \\
Years between displacement and health self-assessment & 0.003 & $(.004)$ \\
Displaced and bachelor's degree 1,2 & $-0.199^{*}$ & $(.085)$ \\
Displaced and some college 1,2 & -0.138 & $(.097)$ \\
Reference group: displaced and high school only & & \\
Wisconsin UR in year of displacement & $-0.047^{*}$ & $(.020)$ \\
Wisconsin UR > 10, in year of displacement & 0.257 & $(.164)$ \\
\hline
\end{tabular}

$$
\begin{aligned}
\mathrm{N} & =11566 \\
* & <=.05 \\
* * & <=.01
\end{aligned}
$$

All models include the full set of variables shown in Table 3, Model 1, including the variables for other types of job loss.

${ }^{1}$ The two interaction terms: 1) displaced and bachelor's degree, and 2) displaced and some college are jointly statistically significant at $\mathrm{p}<.05$ in Model $7\left(X^{2}(\mathrm{df}=2)=6.51 ; \mathrm{p}=.039\right)$

2 displaced and bachelor's degree $=$ displaced $*$ bachelor's degree; displaced and some college $=$ displaced $*$ some college

\begin{tabular}{|c|c|c|c|c|}
\hline & \multicolumn{2}{|c|}{$\underline{\text { Model } 8}$} & \multicolumn{2}{|c|}{ Model 9} \\
\hline & $\underline{\text { Coefficient }}$ & Std. Err. & $\underline{\text { Coefficient }}$ & $\underline{\text { Std. Err. }}$ \\
\hline Displaced & 0.218 & $(.117)$ & -0.066 & $(.036)$ \\
\hline Bachelor's Degree & $0.323^{* *}$ & $(.041)$ & $0.296^{* *}$ & $(.039)$ \\
\hline Some College & $0.147^{* *}$ & $(.044)$ & $0.133^{* *}$ & $(.040)$ \\
\hline \multicolumn{5}{|l|}{ Reference group: high school only } \\
\hline Multiple Displacements & -0.051 & $(.077)$ & -0.088 & $(.075)$ \\
\hline Displaced and bachelor's degree $\mathrm{e}^{1,2}$ & $-0.198^{*}$ & $(.084)$ & & \\
\hline Displaced and some college ${ }^{1,2}$ & -0.149 & $(.097)$ & & \\
\hline
\end{tabular}

\section{Table 8}

Impact of Number of Displacements on Health (Ordered Probit Model) 


\begin{tabular}{|c|c|c|c|c|}
\hline & \multicolumn{2}{|c|}{$\underline{\text { Model } 8}$} & \multicolumn{2}{|c|}{$\underline{\text { Model } 9}$} \\
\hline & $\underline{\text { Coefficient }}$ & $\underline{\text { Std. Err. }}$ & $\underline{\text { Coefficient }}$ & Std. Err. \\
\hline Wisconsin UR in year of displacement & $-0.041^{*}$ & $(.020)$ & & \\
\hline Wisconsin UR > 10 in year of displacement & 0.247 & $(.164)$ & & \\
\hline
\end{tabular}

$\mathrm{N}=11566$

* $\mathrm{p}<=.05$

$* * x<=.01$

All models include the full set of variables shown in Table 3, Model 1, including the variables for other types of job loss.

1 The two interaction terms: 1) displaced and bachelor's degree, and 2) displaced and some college are jointly statistically significant at $\mathrm{p}<.05$ in Model $8\left(X^{2}(\mathrm{df}=2)=6.75 ; \mathrm{p}=.034\right)$

2 displaced and bachelor's degree $=$ displaced*bachelor's degree; displaced and some college $=$ displaced*some college

Table 9

Impact of Health on Displacement

\begin{tabular}{|c|c|c|c|c|c|c|c|c|}
\hline \multirow{3}{*}{ Outcome: } & \multicolumn{2}{|c|}{ Model 10} & \multicolumn{2}{|c|}{ Model 11} & \multicolumn{2}{|c|}{ Model 12} & \multicolumn{2}{|c|}{ Model 13} \\
\hline & \multicolumn{2}{|c|}{ Displaced } & \multicolumn{2}{|c|}{ Retirement Displacement } & \multicolumn{2}{|c|}{ Temporary/Seasonal Job Loss } & \multicolumn{2}{|c|}{ Fired or Discharged } \\
\hline & Coefficient & Std. Err. & Coefficient & Std. Err. & Coefficient & Std. Err. & Coefficient & $\underline{\text { Std. Err. }}$ \\
\hline Self-rated health & 0.048 & $(0.081)$ & -0.035 & $(0.113)$ & $-0.230+$ & $(0.121)$ & $-0.339^{*}$ & $(0.140)$ \\
\hline Male & 0.050 & $(0.122)$ & 0.070 & $(0.175)$ & $0.745^{* *}$ & $(0.196)$ & $0.496^{*}$ & $(0.224)$ \\
\hline Bachelor's degree or higher & $-0.502^{* *}$ & $(0.145)$ & -0.218 & $(0.206)$ & $0.644^{* *}$ & $(0.215)$ & 0.397 & $(0.247)$ \\
\hline Some college & -0.199 & $(0.149)$ & -0.108 & $(0.211)$ & $0.481^{*}$ & $(0.226)$ & -0.137 & $(0.310)$ \\
\hline Widowed/divorced/separated & -0.074 & $(0.159)$ & 0.246 & $(0.206)$ & 0.421 & $(0.223)$ & $0.722^{* *}$ & $(0.243)$ \\
\hline Never been married & 0.423 & $(0.245)$ & -0.120 & $(0.400)$ & 0.289 & $(0.383)$ & 0.419 & $(0.440)$ \\
\hline Professional technical & 0.269 & $(0.198)$ & -0.033 & $(0.273)$ & 0.183 & $(0.293)$ & -0.000 & $(0.342)$ \\
\hline Executive/managerial & $0.813^{* *}$ & $(0.177)$ & $0.556^{*}$ & $(0.239)$ & 0.229 & $(0.280)$ & 0.151 & $(0.323)$ \\
\hline Sales & $1.034^{* *}$ & $(0.206)$ & $0.722^{*}$ & $(0.300)$ & -0.015 & $(0.362)$ & 0.094 & $(0.393)$ \\
\hline Farming & 0.403 & $(0.466)$ & 0.607 & $(0.655)$ & -0.104 & $(1.052)$ & 0.423 & $(0.794)$ \\
\hline Administrative & $0.649^{* *}$ & $(0.181)$ & $0.660^{* *}$ & $(0.239)$ & 0.472 & $(0.291)$ & -0.292 & $(0.370)$ \\
\hline Service & 0.396 & $(0.250)$ & 0.351 & $(0.359)$ & 0.279 & $(0.401)$ & 0.053 & $(0.452)$ \\
\hline Construction./Mining & 0.218 & $(0.278)$ & -0.205 & $(0.479)$ & $0.696^{*}$ & $(0.348)$ & -1.578 & $(1.027)$ \\
\hline Manufacturing & $0.733^{* *}$ & $(0.126)$ & $0.844^{* *}$ & $(0.168)$ & $0.634^{* *}$ & (0.196) & $0.672^{* *}$ & $(0.231)$ \\
\hline Health Insurance provided & 0.114 & $(0.161)$ & 0.085 & $(0.258)$ & -0.010 & $(0.264)$ & -0.056 & $(0.312)$ \\
\hline Pension provided & $-0.355^{*}$ & $(0.143)$ & 0.108 & $(0.224)$ & -0.213 & $(0.232)$ & -0.169 & $(0.275)$ \\
\hline Tenure & -0.001 & $(0.001)$ & 0.001 & $(0.001)$ & $-0.005^{* *}$ & $(0.001)$ & $-0.005^{* *}$ & $(0.001)$ \\
\hline Own Business/Self-employed & $-1.133^{* *}$ & $(0.223)$ & $-1.394^{* *}$ & $(0.419)$ & $-1.525^{* *}$ & $(0.415)$ & $-0.893^{*}$ & $(0.392)$ \\
\hline Constant & $-2.649^{* *}$ & $(0.385)$ & $-3.736^{* *}$ & $(0.548)$ & $-2.604^{* *}$ & $(0.578)$ & $-2.073^{* *}$ & $(0.659)$ \\
\hline Observations & 4,746 & & 4,746 & & 4,746 & & 4,746 & \\
\hline
\end{tabular}

*** $₫ 5.01$,

* $₫ \$ .05$

Soc Sci Res. Author manuscript; available in PMC 2016 July 01. 
Table 10

Health Comparisons: WLS and NHIS* 1993 and 2004

\begin{tabular}{|l|l|l|l|l|}
\hline Health Rating & WLS 1993 & $\underline{\text { NHIS 1993 }}$ & $\underline{\text { WLS 2004 }}$ & NHIS 2004 \\
\hline Excellent & $28.8 \%$ & $29.9 \%$ & $20.1 \%$ & $19.6 \%$ \\
Very Good & & $30.5 \%$ & & $34.3 \%$ \\
Good & $59.8 \%$ & $28.2 \%$ & $63.4 \%$ & $33.3 \%$ \\
Fair & $9.8 \%$ & $7.0 \%$ & $12.8 \%$ & $9.4 \%$ \\
Poor & $1.6 \%$ & $4.3 \%$ & $2.2 \%$ & $3.4 \%$ \\
Very Poor & $0.4 \%$ & & $0.3 \%$ & \\
\hline
\end{tabular}

Includes non-Hispanic white NHIS respondents born in 1939 who have at least a high school diploma

Table 11

Health by Displacement Status

\begin{tabular}{|l|r|r|r|r|}
\hline & \multicolumn{2}{|c|}{ Displaced } & \multicolumn{2}{c|}{ Not Displaced } \\
\hline Health Rating & $\underline{\text { Frequency }}$ & $\underline{\text { Percent }}$ & $\underline{\text { Frequency }}$ & $\underline{\text { Percent }}$ \\
\hline Excellent & 407 & $21.1 \%$ & 2490 & $25.8 \%$ \\
Good & 1241 & $64.5 \%$ & 5896 & $61.2 \%$ \\
Fair & 226 & $11.7 \%$ & 1072 & $11.1 \%$ \\
Poor & 40 & $2.1 \%$ & 150 & $1.6 \%$ \\
Very Poor & 11 & $0.6 \%$ & 33 & $0.3 \%$ \\
\hline
\end{tabular}




\section{Highlights}

- The impact of job loss on health is worse when unemployment is high.

- The impact of job loss on health is worse for persons with a bachelor's degree.

- Persons displaced in a strong economy, experience minimal health consequences. 


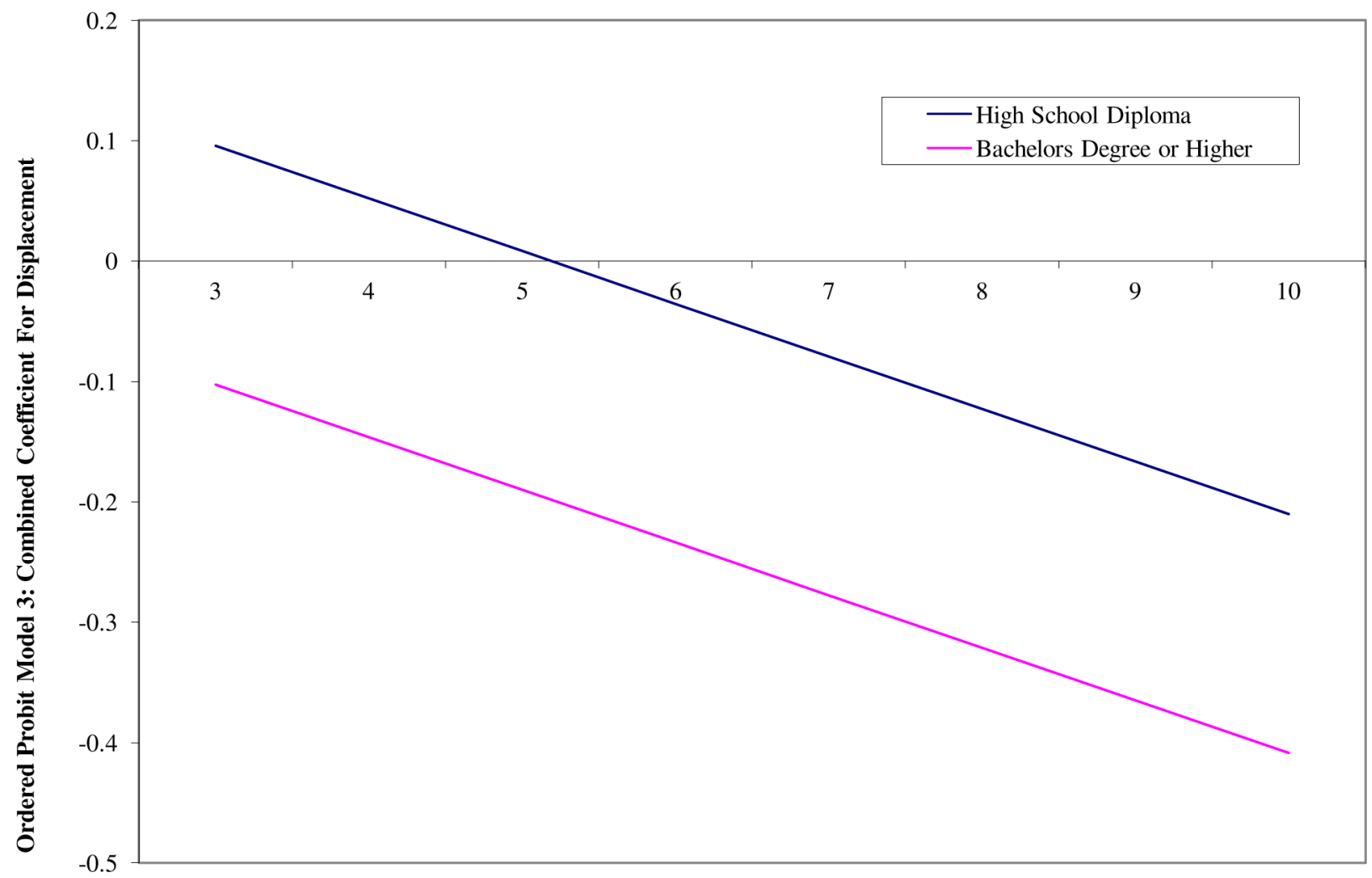

Wisconsin Unemployment Rate in Year of Displacement

Figure 1.

Impact (Combined Coefficient) of Displacement on Self-Rated Health by Wisconsin Unemployment Rate in Year of Displacement (Ordered Probit Model 3) 


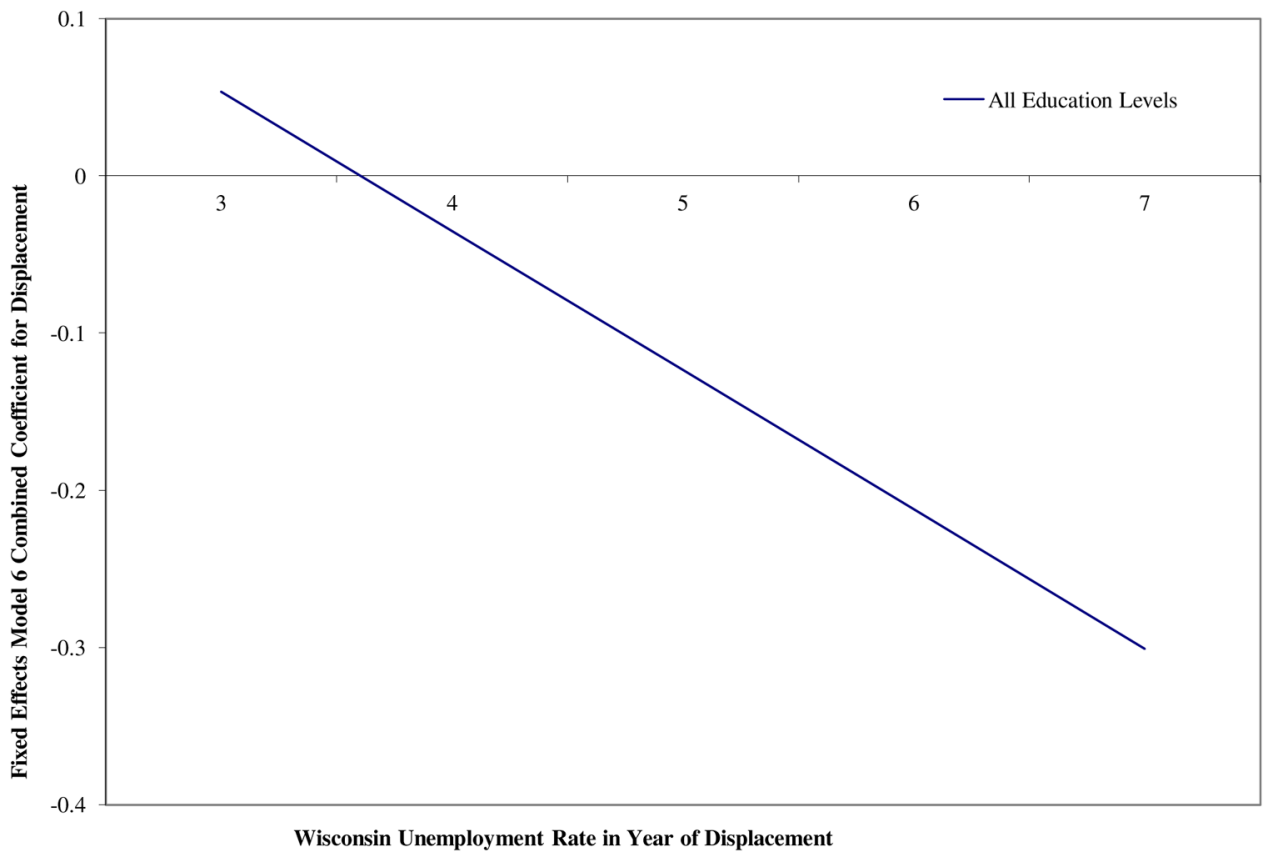

Figure 2.

Impact (Combined Coefficient) of Displacement on Self-Rated Health by Wisconsin Unemployment Rate in Year of Displacement (Fixed Effects Model 6) 


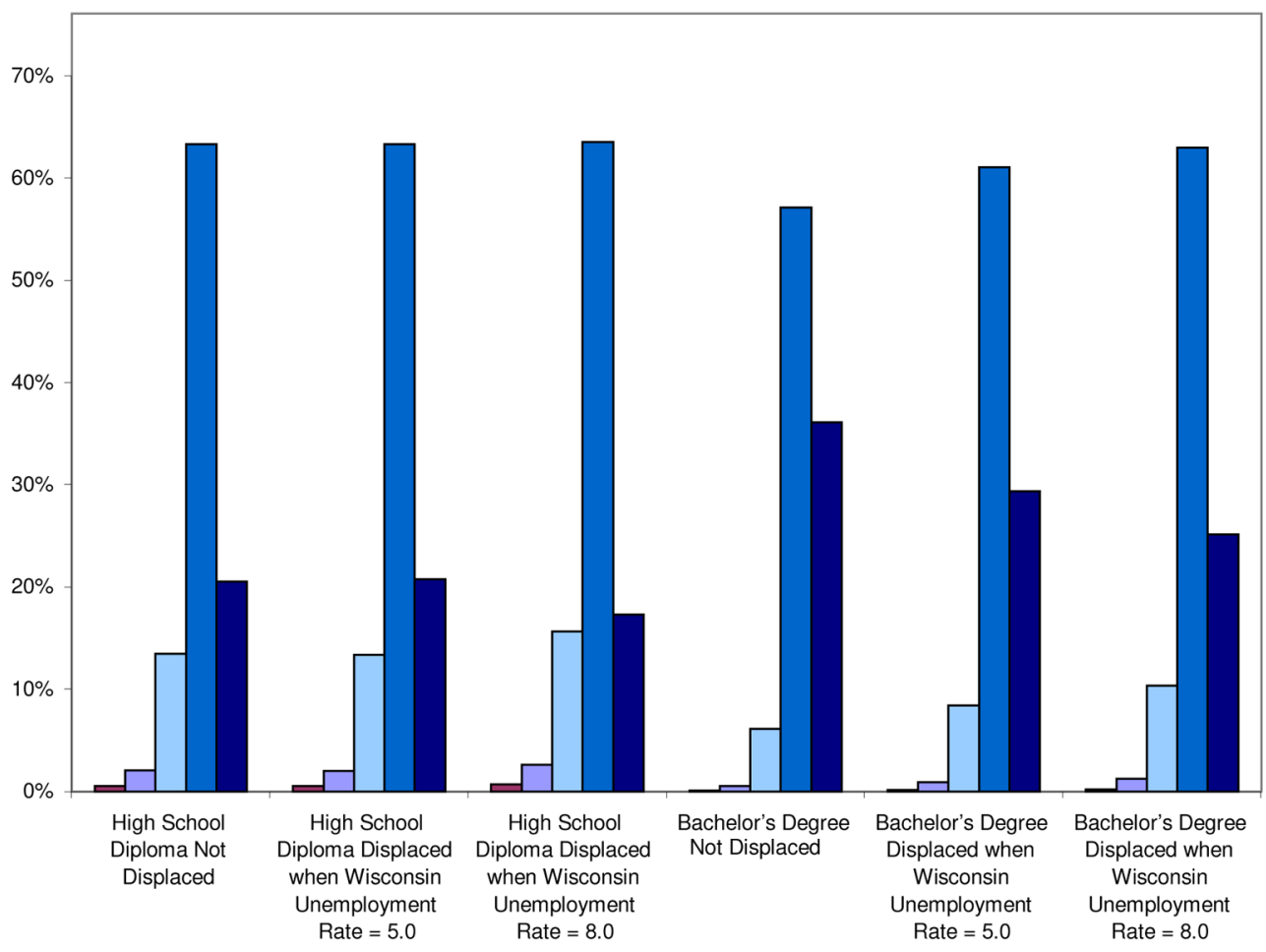

$\square$ Very Poor Health $\square$ Poor Health 口Fair Health aGood Health Excellent Health

Figure 3.

Ordered Probit Simulated Probabilities of Self-Rated Health 


\section{Table 1}

\section{Variables Used}

\begin{tabular}{|c|c|}
\hline$\underline{\text { Variable }}$ & WLS Description \\
\hline Health Outcome & self-rated health 5 point scale: very poor, poor, fair, good, excellent \\
\hline \multicolumn{2}{|l|}{$\underline{\text { Job Loss }}$} \\
\hline Displacement & displaced at some point since 1975 \\
\hline Other Types of Involuntary Job Loss & $\begin{array}{l}\text { retirement displacement, fired, temporary/seasonal layoff, business failure, left job for health } \\
\text { reasons }\end{array}$ \\
\hline \multicolumn{2}{|l|}{$\underline{\text { Moderating Effects }}$} \\
\hline $\begin{array}{l}\text { Economic Conditions in year of } \\
\text { Displacement }\end{array}$ & $\begin{array}{l}\text { Wisconsin unemployment rate in the year of displacement. Variable }=0 \text { if respondent was not } \\
\text { displaced. }\end{array}$ \\
\hline $\begin{array}{l}\text { Educational Attainment for those } \\
\text { experiencing Displacement }\end{array}$ & $\begin{array}{l}\text { displaced and attended some college; displaced and have bachelor's degree or higher, displaced } \\
\text { and high school diploma only (reference category) }\end{array}$ \\
\hline \multicolumn{2}{|l|}{ Demographic Controls } \\
\hline Age & $(54$ or 65$)$ \\
\hline Sex & male/female \\
\hline Marital Status & married, never been married, widowed/divorced/separated \\
\hline Educational Attainment & $\begin{array}{l}\text { high school diploma (no college), some college (less than a bachelor's degree), bachelor's } \\
\text { degree or higher }\end{array}$ \\
\hline \multicolumn{2}{|l|}{ Family Background } \\
\hline Parents SES Factor Score & $\begin{array}{l}\text { Index from factor analysis (by WLS staff) including mother's education, father's education, } \\
\text { father's occupation and household income at age } 18 .\end{array}$ \\
\hline \multicolumn{2}{|l|}{$\begin{array}{l}\text { Employment Context Associated with } \\
\text { Displacement and Health }\end{array}$} \\
\hline Industry & whether the respondent has ever been employed in manufacturing, mining and construction \\
\hline Occupation & $\begin{array}{l}8 \text { variables measuring whether the respondent has ever been employed in each of the following } \\
\text { eight occupational groups: professional/technical, managerial, administrative, sales, service, } \\
\text { skilled worker/operator/laborer, farmer, military }\end{array}$ \\
\hline Income & earnings at age $36(1975)$ \\
\hline
\end{tabular}


Table 2

Summary of Variables Used in Analysis

\begin{tabular}{|c|c|c|}
\hline$\underline{\text { Variables }}$ & $\underline{\text { Mean/Percentage }}$ & $\underline{\text { Standard Deviation }}$ \\
\hline Self-Rated Health $=$ Excellent & $25.1 \%$ & \\
\hline Self-Rated Health = Good & $61.7 \%$ & \\
\hline Self-Rated Health $=$ Fair & $11.2 \%$ & \\
\hline Self-Rated Health $=$ Poor or Very Poor & $2.0 \%$ & \\
\hline Experienced Displacement & $16.6 \%$ & \\
\hline Displaced when Wisconsin Unemployment Rate $=3.1-4.9$ & $6.9 \%$ & \\
\hline Displaced when Wisconsin Unemployment Rate $=5.0-6.9$ & $5.2 \%$ & \\
\hline Displaced when Wisconsin Unemployment Rate $=7.0-10.0$ & $4.6 \%$ & \\
\hline Displaced when Wisconsin Unemployment Rate $>10.0$ & $0.8 \%$ & \\
\hline Displaced and High School Diploma only & $11.2 \%$ & \\
\hline Displaced and Some College & $2.3 \%$ & \\
\hline Displaced and Bachelor's Degree or higher & $3.1 \%$ & \\
\hline Retirement Displacement & $2.1 \%$ & \\
\hline Business Failure & $0.6 \%$ & \\
\hline Temporary/Seasonal Job Loss & $3.0 \%$ & \\
\hline Fired or Discharged & $5.1 \%$ & \\
\hline Left Job for Health Reasons & $7.3 \%$ & \\
\hline Year is $1992-3$ (age is approximately 54 ) & $52.3 \%$ & \\
\hline Male & $47.2 \%$ & \\
\hline Never Been Married & $4.1 \%$ & \\
\hline Widowed/Divorced Separated & $14.9 \%$ & \\
\hline High School Diploma Only (No College) & $60.7 \%$ & \\
\hline Some College & $13.5 \%$ & \\
\hline Bachelor's Degree or Higher & $25.8 \%$ & \\
\hline Ever employed in Manufacturing, Mining or Construction Industries & $35.6 \%$ & \\
\hline Ever employed in the following occupation: & & \\
\hline Professional/Technical & $31.6 \%$ & \\
\hline Executive/Managerial & $28.6 \%$ & \\
\hline Administrative/Clerical & $31.1 \%$ & \\
\hline Sales & $20.7 \%$ & \\
\hline Skilled Craft, Operator or Laborer & $27.9 \%$ & \\
\hline Service & $15.4 \%$ & \\
\hline Military & $0.1 \%$ & \\
\hline Farming & $5.0 \%$ & \\
\hline Earnings in 1975 (in 2004 dollars) & $\$ 33,447$ & $\$ 36,810$ \\
\hline Parents SES 1957 Factor Score & 16.3 & 11.2 \\
\hline
\end{tabular}

$\mathrm{N}=11566$ (for 1975 earnings, $\mathrm{N}=10432$ ) 
Table 3

Impact on Self-Rated Health: Ordered Probit Initial Model

\begin{tabular}{|lcc|}
\hline & \multicolumn{2}{c|}{ Model 1 } \\
\hline Displaced & $\underline{\text { Coefficient }}$ & $\underline{\text { Std. Err. }}$ \\
Retirement Displacement & $-0.079^{*}$ & $(0.034)$ \\
Temporary/Seasonal Job Loss & -0.071 & $(0.071)$ \\
Fired/Discharged & $-0.157^{*}$ & $(0.061)$ \\
Left Job for Health Reason & -0.054 & $(0.055)$ \\
Business Failure & $-0.891^{* *}$ & $(0.051)$ \\
Year is 1993 (age is approximately 54) & -0.023 & $(0.164)$ \\
Bachelor's Degree (or more) & $0.171^{* *}$ & $(0.018)$ \\
Some College & $0.296^{* *}$ & $(0.039)$ \\
Reference group: High School only (no college) & $0.122^{* *}$ & $(0.040)$ \\
Widowed/Divorced/Separated & & \\
Never Been Married & $-0.116^{* *}$ & $(0.035)$ \\
Reference group: currently married & $-0.332^{* *}$ & $(0.064)$ \\
Earnings 1975 (in \$1,000s) & & \\
Parents SES 1957 & -0.013 & $(0.036)$ \\
Male & $0.104^{* *}$ & $(0.031)$ \\
Ever employed in the following industries/occupations: & & \\
Manufacturing/Mining/Construction & $-0.116^{* *}$ & $(0.031)$ \\
Professional/Technical & $0.112^{* *}$ & $(0.033)$ \\
Executive/Managerial & $0.091^{* *}$ & $(0.030)$ \\
Military & 0.503 & $(0.332)$ \\
Farming & -0.006 & $(0.053)$ \\
Service & $0.002^{* *}$ & $(0.000)$ \\
Administrative/Clerical & $(0.001)$ \\
Sales & & \\
Craft/Operator/Laborer & & \\
\hline
\end{tabular}

\footnotetext{
$\mathrm{N}=11566$

p $<=.05$

** $\mathrm{p}<=.01$
} 
Table 4

Impact on Self-Rated Health: Initial Fixed Effects Model

\begin{tabular}{|lcc|}
\hline & $\underline{\text { Model 4 }}$ \\
\hline Displaced & $\underline{\text { Coefficient }}$ & $\underline{\text { Std. Err. }}$ \\
Retirement Displacement & $-0.073^{*}$ & $(0.035)$ \\
Temporary/Seasonal Job Loss & -0.010 & $(0.050)$ \\
Fired/Discharged & -0.035 & $(0.053)$ \\
Left Job for Health Reason & 0.041 & $(0.063)$ \\
Business Failure & $-0.334^{* *}$ & $(0.037)$ \\
Year is 1993 (age is @54) & -0.061 & $(0.117)$ \\
Widow/Divorced/Separated & $0.172 * *$ & $(0.025)$ \\
Never Been Married & 0.052 & $(0.031)$ \\
Reference group: Currently Married & -0.137 & $(0.251)$ \\
Ever employed between 1993-2004 in the following industry/occupation Manufacturing/Mining/Construction & 0.022 & $(0.024)$ \\
Professional/Technical & 0.042 & $(0.026)$ \\
Executive/Managerial & & $(0.025)$ \\
Military & 0.017 & $(0.384)$ \\
Farming & -0.222 & $(0.048)$ \\
Service & 0.038 & $(0.031)$ \\
Administrative/Clerical & $0.026)$ \\
Sales & 0.048 \\
Craft/Operator/Laborer & 0.036 & $(0.029)$ \\
\hline
\end{tabular}

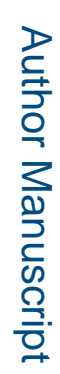

$\mathrm{N}=9682$

p $<=.05$

** $\mathrm{p}<=.01$ 


\section{로을}

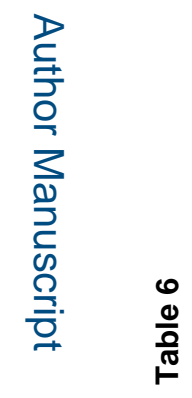

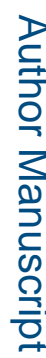
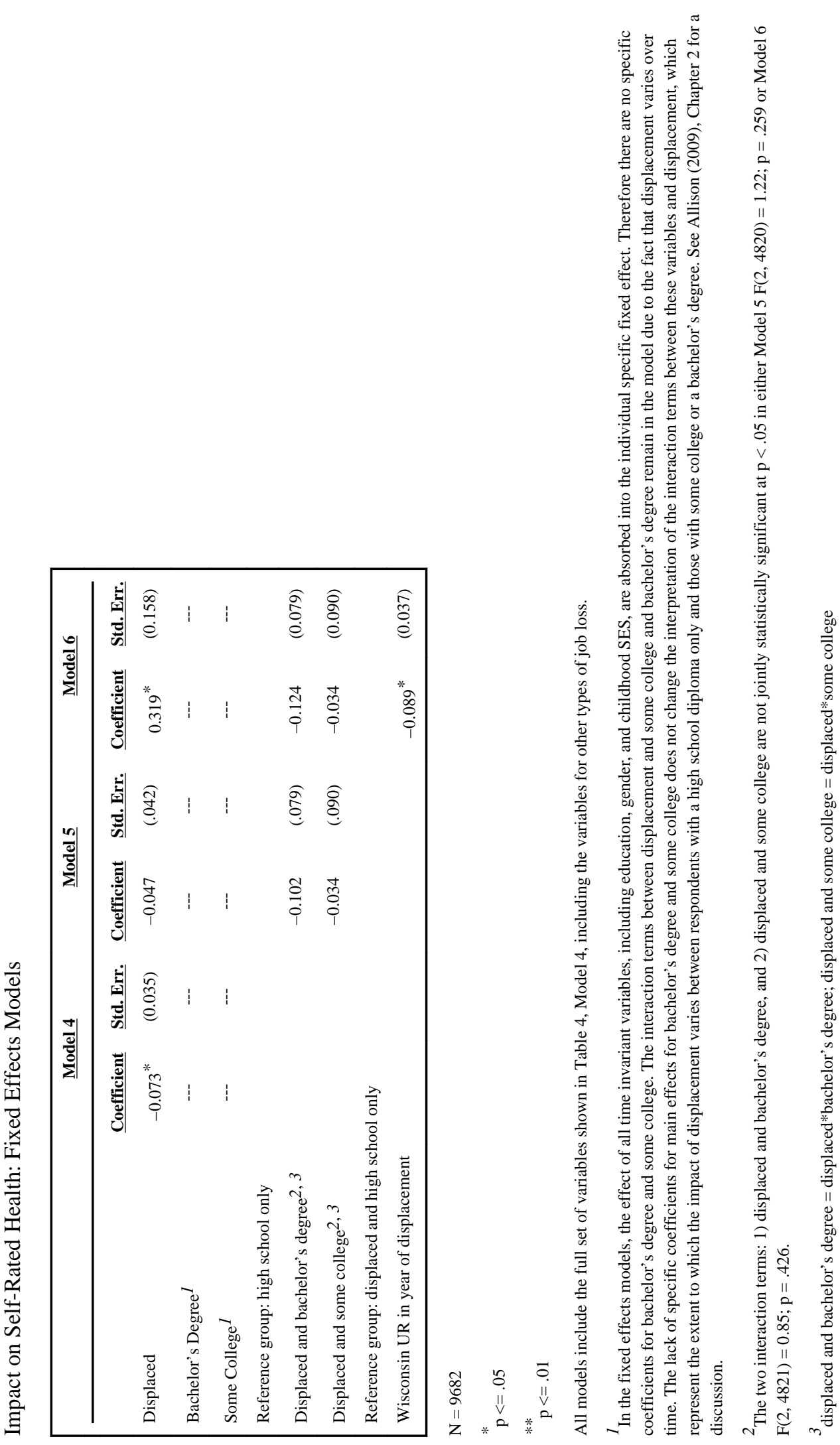

Soc Sci Res. Author manuscript; available in PMC 2016 July 01. 